\title{
INTERNATIONAL SURVEY ABOUT PROPHYLACTIC ANTIBIOTICS AND VACCINATION IN SICKLE CELL DISEASE CHILDREN. DO WE DO SO DIFFERENT?
}

C. Epalza ${ }^{1}$, E. Rincón ${ }^{2}$, E. Cela², K. Ramesh ${ }^{3}$, R.H. Almaghrabi ${ }^{4}$, S. Lobitz ${ }^{5}$, B. Mbiya ${ }^{6}$, S. Trompeter ${ }^{7}$, A. Pepe ${ }^{8}$, E. Petras ${ }^{9}$, B. Kadima Tshimanga ${ }^{10}$, B. Inusa ${ }^{11}$, C. Komuhangi ${ }^{12}$, E. Berezin ${ }^{13}$, A. de Pagter ${ }^{14}$, B. Koehl ${ }^{15}$, M. Sundin ${ }^{16}$, F. Alfares ${ }^{17}$, P. Giordano ${ }^{18}$, B. Pujol ${ }^{19}$, A. Vanderfaeillie ${ }^{20}$, in behalf of SPRING.

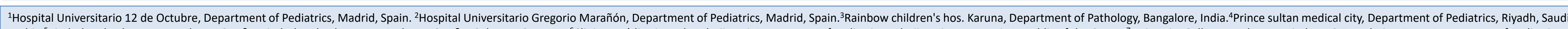

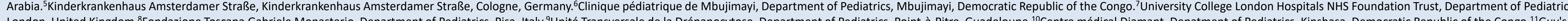

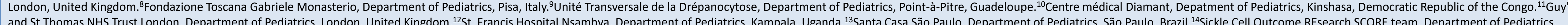

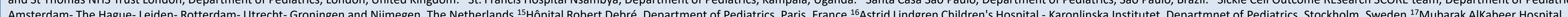

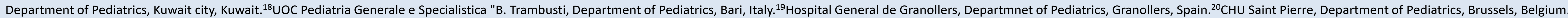

Introduction and aim: Vaccination and prophylactic antibiotic are the cornerstone of Sickle Cell Disease (SCD) children infections' prevention. Conditions to stop antibioprophylaxis remain controversial. Our aim is to describe current practice in preventive measures in SCD children.

ESP18-1097

Methods: An online survey was conducted in January 2018 among members of the Sickle cell disease Pediatric Research about Infections Group (SPRING). SPRING is a group that assembles physicians all over the world interested in infectious diseases in SCD children.

Results: From 23 centers contacted, 19 (83\%) completed the survey. These centers treat in total more than 5000 SCD patients.

19 PARTICIPATING CENTERS

South America (Brasil)

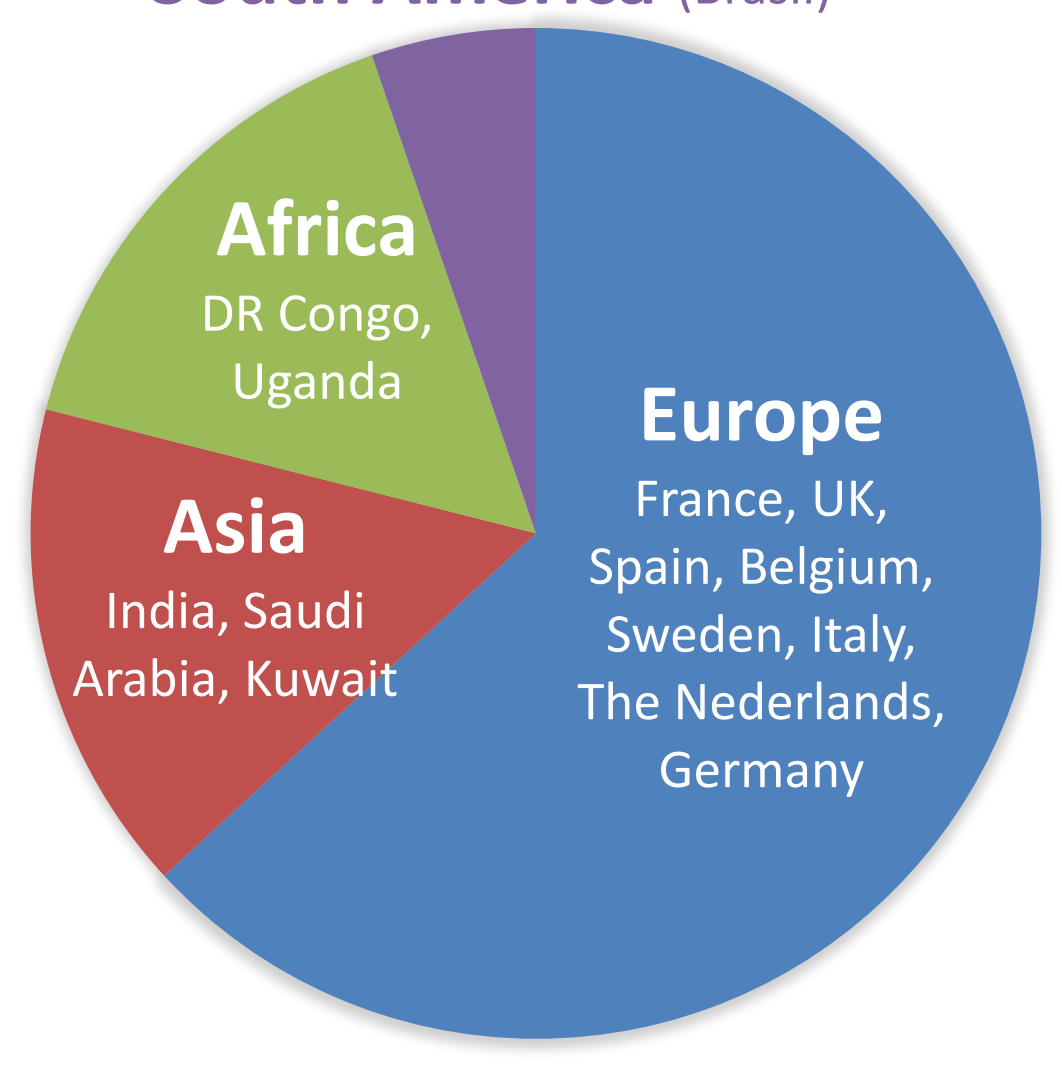

PRESCRIBED ANTIBIOPROPHYLAXIS

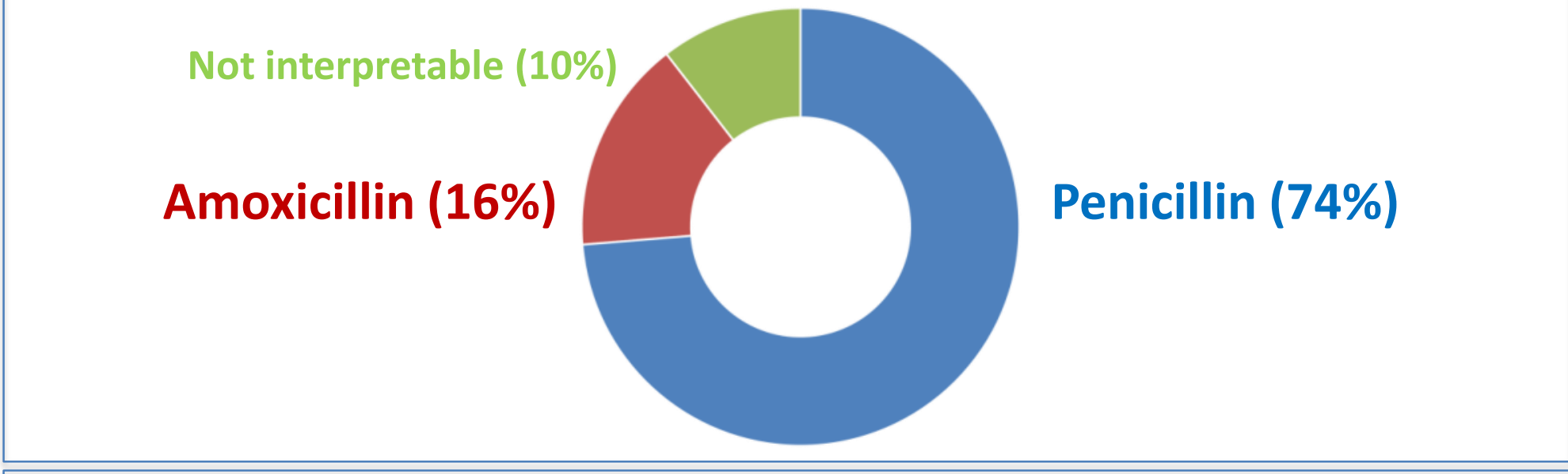

AGE TO STOP ANTIBIOPROPHYLAXIS

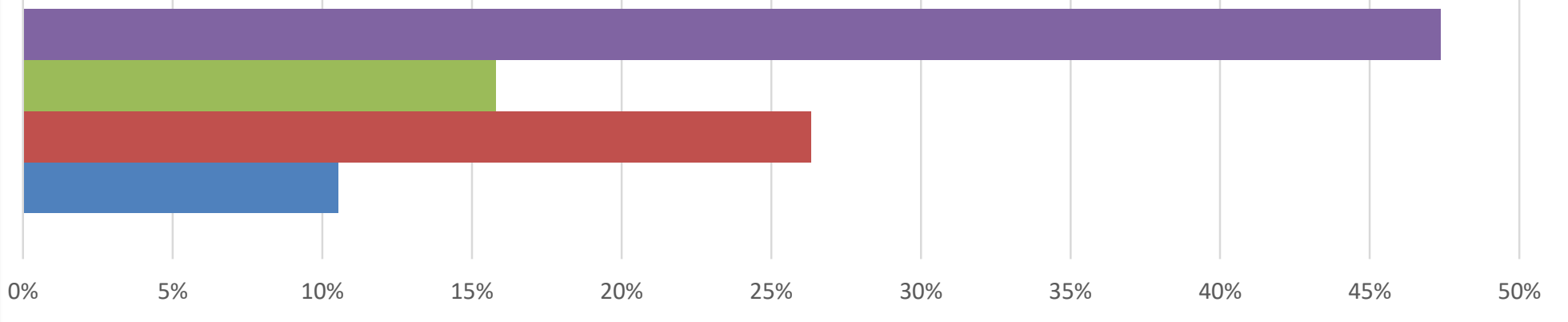

$\square$ At 5 years-old $\square$ At 10-12 years-old $\square$ At Adulthood $\square$ Not interpretable

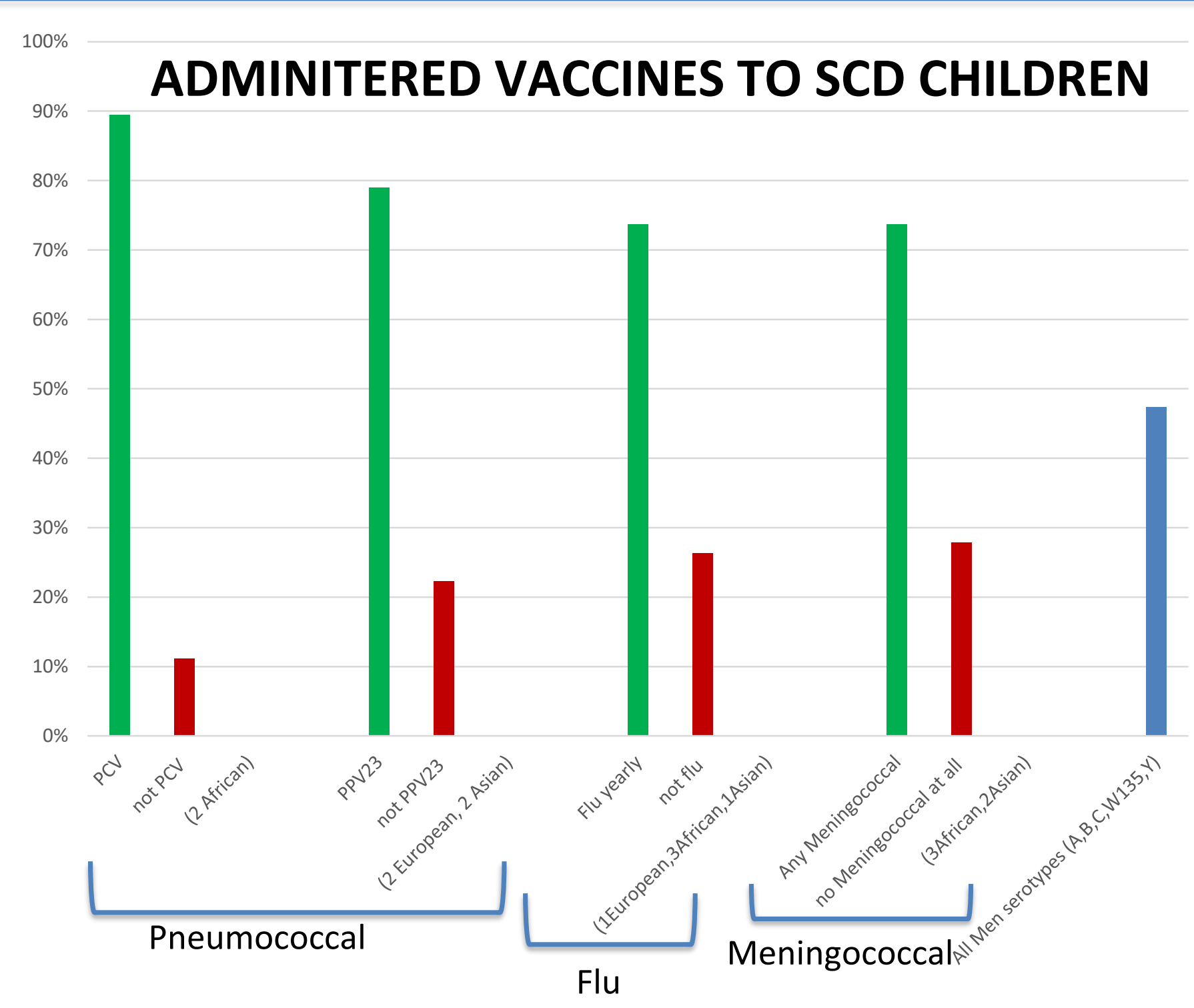

Conclusions: Although there is consensus to give penicillin as prophylaxis to SCD children, age to stop remains a dilemma, with different attitudes even among centres from the same continent. SCD vaccination programs differ greatly depending on continents. 